\title{
Construção de um Jogo Usando Robótica para a Formação de Habilidades de Programação em Crianças
}

\author{
William Teles de Andrade \\ Junior \\ Instituto Federal de Educação, \\ Ciências e Tecnologia de Pernambuco \\ (IFPE) - Campus Paulista \\ Paulista, Pernambuco, Brasil \\ wtaj@discente.ifpe.edu.br
}

\author{
Julia Yasmim de Castro Silva \\ Instituto Federal de Educação, \\ Ciências e Tecnologia de Pernambuco \\ (IFPE) - Campus Paulista \\ Paulista, Pernambuco, Brasil \\ jycs@discente.ifpe.edu.br
}

\author{
Gaston Alexandre Gouveia \\ Instituto Federal de Educação, \\ Ciências e Tecnologia de Pernambuco \\ (IFPE) - Campus Paulista \\ Paulista, Pernambuco, Brasil \\ gag1@discente.ifpe.edu.br
}

\author{
Gabriel Lima Gonçalves da \\ Silva \\ Instituto Federal de Educação, \\ Ciências e Tecnologia de Pernambuco \\ (IFPE) - Campus Paulista \\ Paulista, Pernambuco, Brasil \\ glgs@discente.ifpe.edu.br
}

\begin{abstract}
RESUMO
Constant technological advances have made society face the need to acquire new skills, one of which is programming. At first, this activity was aimed only at computer professionals, but it aroused educators' interest and has been incorporated as part of the school curriculum. Therefore, some initiatives try to present programming to children using different approaches. Our proposal focuses on programming using robotics. The work shows the development of a robot created with Arduino to be used in an educational game. In the proposal, the player needs to develop the robot's algorithm to move to a goal on the map in the game. An Android application controls the robot, and the whole proposal is created in a playful manner. Thus, it is expected to create a low-cost tool to stimulate computational thinking.
\end{abstract}

\section{KEYWORDS}

Programação, Pensamento Computacional, Robótica, Arduino, Android

\section{INTRODUÇÃO}

Pensamento Computacional é um termo utilizado para indicar as habilidades de resolução de problemas que ensinam aos indivíduos a pensar e analisar uma situação ou um artefato de forma independente da tecnologia [1]. Para Blikstein [2], aprender a programar é uma forma fundamental de desenvolver essas habilidades. Isso justifica as iniciativas já existentes como o Code.org [3], Scratch [4] que tentam aproximar a programação de crianças.

Segundo Benitti [5], a robótica é uma ótima ferramenta de aprendizado, mesmo para os assuntos que não estão diretamente ligados a essa área. Baseando-se nisso, este trabalho tem como objetivo apresentar a construção de um jogo utilizando robótica para apresentar conceitos básicos de programação e assim estimular o pensamento computacional em crianças. Através de comandos simples de direção, o jogador vai programar a movimentação de um robô num mapa com o intuito de alcançar um objetivo pré-definido.

\section{Rodrigo Cesar Lira da Silva \\ Instituto Federal de Educação, \\ Ciências e Tecnologia de Pernambuco \\ (IFPE) - Campus Paulista \\ Paulista, Pernambuco, Brasil \\ rodrigo.lira@paulista.ifpe.edu.br}

No primeiro ano deste projeto, a proposta foi desenvolvida usando Scratch [6]. Agora, como continuidade da pesquisa, o jogo foi desenvolvido usando programação e Arduino. O resto do trabalho está dividido da seguinte forma: na Seção 2 são indicadas as etapas para criação do jogo. Em seguida, na Seção 3 são apresentados os resultados alcançados até agora no desenvolvimento do jogo utilizando robótica. Por fim, na Seção 4 são apresentadas as conclusões e os trabalhos futuros.

\section{ETAPAS DA CONSTRUÇÃO DO JOGO}

As atividades de desenvolvimento deste trabalho foram divididas em etapas realizadas por quatro alunos extensionistas de nível de graduação que, devido ao distanciamento social imposto pela pandemia do coronavírus, realizaram todas as atividades das suas respectivas residências. As etapas de desenvolvimento foram as seguintes:

- Estudos das tecnologia: Nessa etapa foi desenvolvido um plano de estudo que envolveu os assuntos de eletrônica e Arduino, assuntos nos quais nenhum dos estudantes dominavam por completo. Além disso, um dos alunos ficou responsável por estudar o desenvolvimento Android.

- Construção de códigos e circuitos: A princípio, os códigos e os circuitos utilizados foram desenvolvidos nas ferramentas Tinkercad e Fritzing. Foi também nesta etapa que o aplicativo para controlar o robô foi desenvolvido, utilizando o MIT App Inventor, mas em seguida migrado para Android com Java.

- Montagem do robô: o circuito foi montado em um chassi em formato arrendondado adquirido em um site especializado ${ }^{1}$, porém nos testes preliminares percebeu-se a necessidade de mudança. Por esse motivo, todo o circuito foi migrado para o chassi Falcon ${ }^{2}$.

- Criação do mapa: as dimensões do mapa foram definidas de acordo com a análise da movimentação do robô. Além do

\footnotetext{
https://www.filipeflop.com/produto/kit-chassi-redondo-2wd-robo/

${ }^{2}$ https://www.robocore.net/robotica-robocore/plataforma-robotica-falcon
} 
mapa, foram criadas imagens de elementos para o cenário do jogo.

\section{SOLUÇÃO PROPOSTA}

O jogo proposto teve um custo de fabricação de aproximadamente $\mathrm{R} \$ 350,00$ e é composto por um aplicativo Android, um robô construído usando Arduino Uno, um mapa impresso em lona de banner e elementos que representam os objetivos e os obstáculos do mapa. O mapa, o robô e os elementos que compõem o cenário podem ser observados na Figura 1.

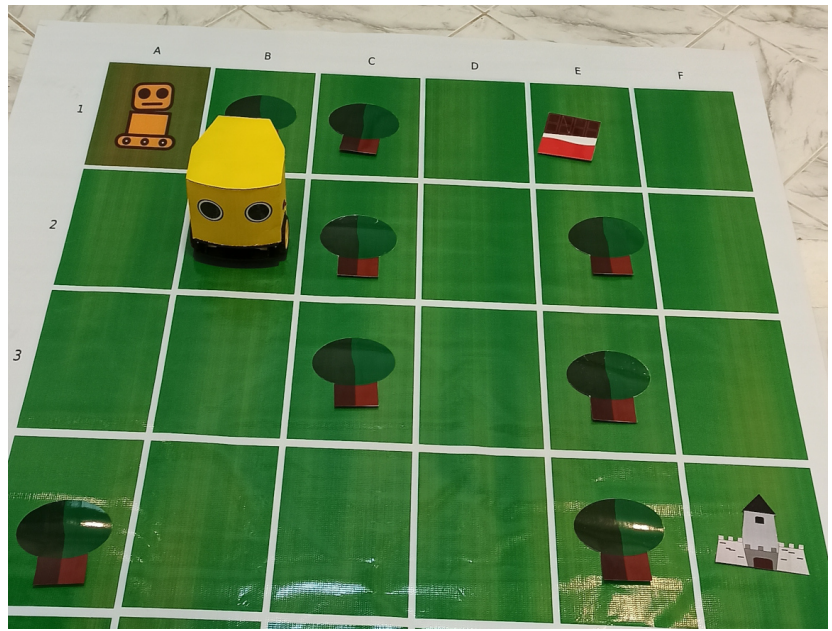

Figura 1: Mapa, o robô e os elementos que compõem o cenário do jogo. Fonte: Próprio autor.

Toda a interação com o robô é realizada através de um aplicativo (Figura 2) desenvolvido com o Android SDK. Nele, é informado o objetivo a ser atingido na movimentação do robô. É também através dele que o jogador se conecta ao robô e cria o algoritmo da movimentação.

Os componentes principais utilizados na montagem robô foram: módulo HC-05 para comunicação bluetooth, bateria 18650 como fonte de energia dos motores DC das rodas, uma Ponte H L298N e uma placa Arduino Uno que foi alimentada utilizando uma bateria de 9 v. O circuito do robô é apresentado na Figura 3.

O chassi utilizado foi envolvido com um molde (case) feito em papelão, como pode ser visto na Figura 4, e pintado com tinta amarela. Nele foram adicionados dois olhos para indicar o sentido da movimentação do robô, também foi colocado um interruptor para desligar o circuito. No vídeo ${ }^{3}$ é apresentado a movimentação do robô no mapa.

\section{CONSIDERAÇÕES FINAIS}

Muitas iniciativas têm sido desenvolvidas para incentivar o desenvolvimento do pensamento computacional. Este projeto segue

\footnotetext{
${ }^{3}$ https://www.youtube.com/watch?v=mGPX0IX8zXg
}

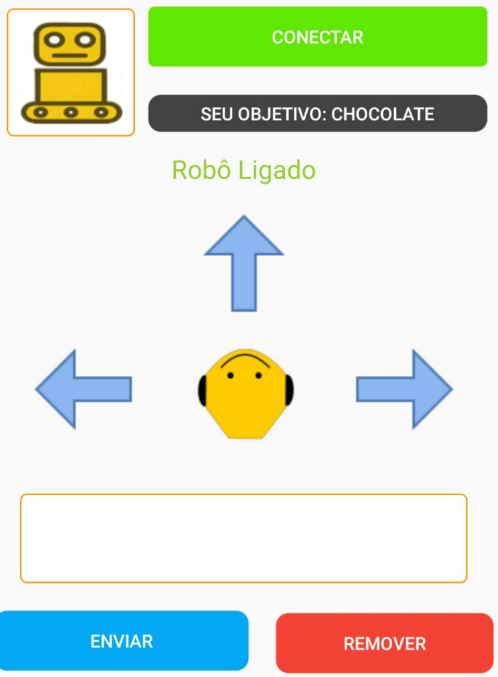

Figura 2: Aplicativo para controle do robô desenvolvido utilizando o Android SDK. Fonte: Próprio autor.

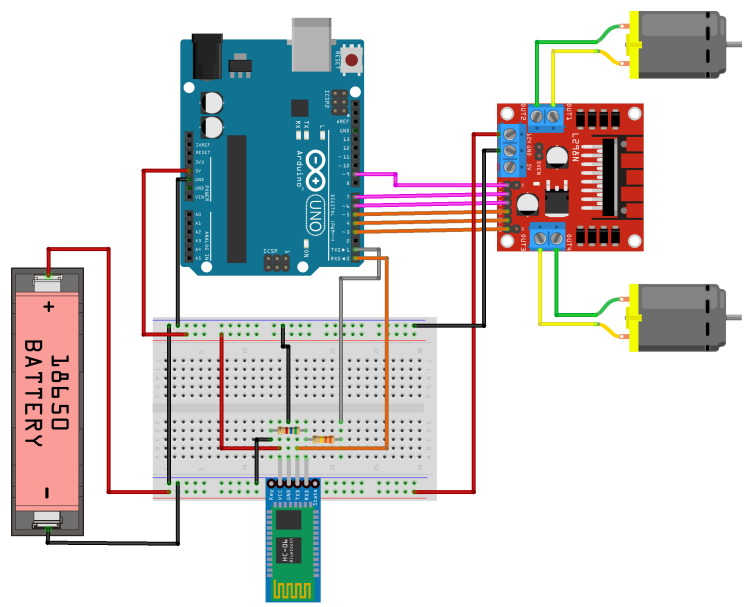

Figura 3: Circuito do robô criado na ferramenta Fritzing. Fonte: Próprio autor.

essa direção, uma vez que demonstra o resultado do desenvolvimento de um jogo baseado em robótica para apresentar conceitos de programação.

No jogo proposto, a cada partida, o jogador é convidado a criar o algoritmo para guiar o robô até um objetivo no mapa. O mapa apresenta um cenário lúdico para atrair a atenção dos jogadores. Toda interação com o robô é realizada através de um aplicativo que utiliza a comunicação bluetooth.

Apesar de estar em um estado avançado de desenvolvimento, alguns ajustes precisam ser realizados para que o exista uma maior precisão na movimentação do robô no cenário do mapa. Além desses ajustes, como trabalho futuro, espera-se desenvolver um chassi próprio em MDF e aplicar o jogo numa turma de ensino fundamental da cidade de Paulista-PE. 


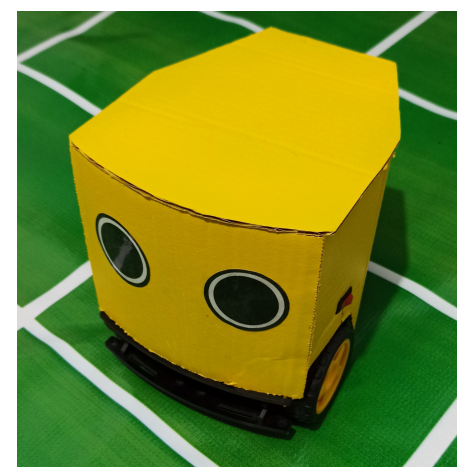

Figura 4: Robô desenvolvido para o jogo. A direita é possível ver o interruptor que desliga o circuito. Fonte: Próprio autor.

\section{AGRADECIMENTOS}

Os autores deste trabalho agradecem o apoio financeiro do Programa Institucional de Bolsas de Extensão (PIBEX) do Instituto Federal de Educação, Ciências e Tecnologias de Pernambuco (IFPE).

\section{REFERÊNCIAS}

[1] Bruno Henrique De Paula, José Armando Valente, and Andrew Burn. O uso de jogos digitais para o desenvolvimento do currículo para a educação computacional na inglaterra. Currículo sem Fronteiras, 14(3):46-71, 2014.

[2] Paulo Blikstein. O pensamento computacional e a reinvenção do computador na educação, 2008. URL http://www.blikstein.com/paulo/documents/online/ol pensamento_computacional.html. Acessado: 30 nov. 2020.

[3] Code.org. Página principal do code.org, 2020. URL https://code.org/. Acessado: 14 dez. 2020.

[4] Scratch. Página principal do scratch, 2020. URL https://scratch.mit.edu/. Acessado: 27 nov. 2020.

[5] Fabiane Barreto Vavassori Benitti. Exploring the educational potential of robotic in schools: A systematic review. Computers Education, 58(3):978 - 988, 2012. ISSN 0360-1315. doi: https://doi.org/10.1016/j.compedu.2011.10.006. URL http: //www.sciencedirect.com/science/article/pii/S0360131511002508.

[6] Rodrigo C. Lira, Matheus Cavalcanti, and Luama de Oliveira. Desenvolvimento de um jogo utilizando robótica para o estímulo do pensamento computacional. In Anais do IV Congresso sobre Tecnologias na Educação, pages 524-529, Porto Alegre, RS, Brasil, 2019. SBC. doi: 10.5753/ctrle.2019.8926. URL https://sol.sbc.org.br/index. $\mathrm{php} / \mathrm{ctrle} / \mathrm{article} / \mathrm{view} / 8926$. 